ORIGINAL ARTICLE

\title{
Maternal Stress Of Hospitalized Children In A Hospital Of Rupandehi, Nepal
}

\author{
Dhungana $\mathbf{M}^{\mathbf{1}}$, Kachapati $\mathbf{A}^{\mathbf{2}}$
}

1 Lecturer, Department of Psychiatry, Devdaha Medical College and Research Institute, Rupendehi, 2. Lecturer, Universal College of Nursing Sciences, UCMS, Teaching Hospital, Bhairahawa, Nepal

E-mail *Corresponding author : drdhungana3536@hotmail.com

\section{Abstract}

Introduction: Illness and hospitalization are often critical events that a child is faced with and the stress of it can affect all family members. Maternal stress and anxiety can also affect the child in two ways, transferring stress to the child and interfering with the mother's ability of childcare. Researcher sought to find out the maternal stressors of hospitalized children in a hospital of Nepal.

Material And Method: A descriptive cross-sectional study was conducted to find out the maternal stressors of hospitalized children among one hundred and five mothers selected through non probability purposive method. The data was collected by using semi-structured interview schedule and data was analyzed by using descriptive and inferential statistics with SPSS software version 16.

Results: The findings of the study revealed that more than half of the mothers $62.8 \%, 58.1 \%, 63.8 \%, 90.4 \%$, $88.6 \%, 78 \%, 83.8 \%$ and $87.7 \%$ had very high stress related to child factors; child appears lethargic, weak and pale, prolongation of hospitalization, uncertain try about future of child's medical condition, fear of relapse, child irritability and crying, in concern about IV fluids and tubes connected, child's pain, and about laboratory and imaging respectively. Majority of mothers had stress related to social and economic aspects, 59\% for failure to provide comfort to other children due to child illness, $82.8 \%$ had stress regarding being away from work and living place. Regarding stressors related to environmental factors, Majority 54.2\% mothers had very high stress from equipments, $84.7 \%$ mothers had very high stress on unfamiliar environment, $68.5 \%$ had very high stress for lack of adequate sanitation and air pollution, $59 \%$ had very high stress that no room to rest for visitor. Regarding stressors related to hospital staffs, $78 \%$ mothers had very high stress for giving the responsibility for monitoring IV fluids, $74.2 \%$ had very high stress for turning over responsibility for collecting samples to mothers by nursing staffs, $60.9 \%$ mothers had very high stress on lack of attention from nursing staffs about mother's problem and $68.5 \%$ had very high stress on lack of proper nutrition for hospitalized children.

Conclusion: Based on the study findings, it is concluded that mothers were passionate in taking care of their child. Most mothers had recognized that illness and hospitalization of their children had an overwhelming psychological and emotional impact on their own behavior and they did not have enough control over their reactions. Therefore, special attention should be given to identify the stressors in nursing care, planning and parents' education, moving stressors and treatment in the same direction and the factors that can reduce the mother's ability to provide childcare and delay in treatment progress.

Keywords: Maternal Stress, Hospitalized Children, Nepal

\section{INTRODUCTION}

Parents have an important role in the promotion of their children's health, being the primary agents involved in direct care, providing access to health services and modeling attitudes and behaviors that influence children's wellbeing. ${ }^{1}$ 
Maternal stress and anxiety can also affect the child in two ways, transferring stress to the child and interfering with the mother's ability of childcare. Currently, in many countries, given the importance of family-centered care, the mother stays at the child's bedside for the entire time of hospitalization and participates in the process of taking care of the child. ${ }^{2}$

Having a child hospitalized is a stressful event for parents who often experience anxiety and depression during the period of hospitalization. According to classical definition $^{3}$, stress is a non-specific response of the body to any excessive environmental request. The reaction to stress is not directly related to the exposure to stressors but is mediated by the individual emotional response. Stress is, in fact, a process embracing several components including stressors, defined as events that pose a challenge to the subject, psychosocial mediators, constructs that enable the subject to evaluate the nature of the situation, and the stress response, typically a measure of the emotional reaction elicited in response to the stressor. ${ }^{4}$

Many aspects of the parents' life will change during hospital stay, including their natural needs, and social and economic issues, which can cause stress and anxiety for the parents. ${ }^{5}$

Feelings of stress and anxiety are often associated with the lack of information on diseases and medical procedures. The pain is caused by the imposed treatments, unfamiliarity with the hospital rules and regulations, unfriendly staff and being afraid of asking questions. $^{6}$ Based on previous studies, factors that cause stress in mothers of hospitalized children are environmental factors, managerial factors; socioeconomic factors and factors that are related to the child's circumstances. ${ }^{7}$ A higher level of family stress can reduce the ability of the mother to cope with problems. ${ }^{8}$ Nurses and parents have different perceptions of stressors in the child's admission to a hospital. In other words, efforts that the hospital staff makes to reduce stress for parents may not be effective. It is not helpful and increases their stress levels too. ${ }^{9}$

\section{MATERIAL AND METHOD}

A descriptive cross-sectional design was adopted to find out the maternal stress of hospitalized children among mothers. The study was conducted in NICU and pediatric wards of Devdaha Medical College and Research Institute, Rupandehi, Nepal among 105 mothers, were selected in the study sample through non probability purposive technique. Semistructured interview schedule was developed by researchers by reviewing the related literatures and consulting with the subject experts.

The researchers reached every ward and obtained the written informed consent with each mothers after a day of admission for enrollment in this study with semi-structured interview schedule. Data collection was done within 3 months (September to November 2018).

Administrative and ethical approval was obtained from the concerned authorities prior to data collection. Descriptive and inferential statistical method was used with SPSS version 16 to analyze our data.

The interview schedule was consisted of two parts: Part I: related to socio-demographic variables and Part II: related to stressors.

The study was conducted from September to November 2018 in Devdaha Medical College, and Research Institute, Rupendehi, Nepal. The exclusion criteria were those who were not willing to participate. All the collected data were analyzed by using descriptive statistics and inferential statistics with Statistical Package for Social Sciences (SPSS) software version 16.

\section{RESULT}

Most (33.6\%) of the mothers were between 24-29 years of age, $29.5 \%$ mothers belong to Brahmin/Chhetri by their caste, $67.7 \%$ mothers were residing in joint families, the education level $81.9 \%$ mothers were literate, $79.1 \%$ mothers had informal occupation. One-hundred and two $(97.1 \%)$ of the mothers had their husbands. Regarding their husband's education $80.4 \%$ were literate, $55.8 \%$ had formal occupation. Regarding the number of children, $39.1 \%$ of the mothers had only one child, $43.8 \%$ had two children and $17.1 \%$ had three or more children.

Age of admitted children; $54.2 \%$ children were under one year old, and $19.3 \%$ children were above 6 years old. Among them $63.8 \%$ children were male and $36.2 \%$ were female, $34.7 \%$ had one day of hospitalization and $20 \%$ were hospitalized for five days or more. 
Regarding the number of hospitalizations, $45.4 \%$ were hospitalized for the first time and $68.6 \%$ were admitted as emergency inpatients.

As per stressors related to child factors (Table 1), $62.8 \%$ mothers had very high stressors that the child appears lethargic, weak and pale, 58.1\% had very high in prolongation of hospitalization, $45.7 \%$ had very high that the child's enabled to eat. Regarding fear of death $38 \%$ had very high stress, $63.8 \%$ had uncertain try about future of child's medical condition, and $90.4 \%$ had stress related to fear of relapse. Around $88.6 \%$ mothers had very high stressors related to child irritability and crying, $78 \%$ mothers had very high stressors in concern about IV fluids and tubes connected, $83.8 \%$ had very for child's pain and $87.7 \%$ had very high concern about laboratory and imaging.

As per the table 2 stressors related to social and economic aspects, 59\% mothers had very high stressors for failure to provide comfort to other children due to child illness, 38\% mothers had average stress to problems related drug availability, $44.7 \%$ mothers had very high stress for inability to pay the costs of treatment and care. Majority $68.8 \%$ mothers had no stress related to concern about academic and school, $55.2 \%$ mothers feel stress fear of other children having the same disease. Regarding fear of job loss because of the child's disease $94.2 \%$ had no stress and $82.8 \%$ mothers had very high stress regarding being away from work and living place.

Regarding stressors related to environmental factors(Table 3), $45.7 \%$ mothers had average stress for noise pollution, $89.6 \%$ mothers had no stress for crowded room and the large number of children, $29.5 \%$ mothers had average stress for uncomfortable beds. Majority 54.2\% mothers had very high stress from equipments, $84.7 \%$ mothers had very high stress on unfamiliar environment, $68.5 \%$ had very high stress for lack of adequate sanitation and air pollution, $46.6 \%$ had very high stress related to no game room for children, 59\% had very high stress that no room to rest for visitor and $49.5 \%$ had very high stress regarding shortage of blankets and linens.

Regarding stressors related to hospital staffs (Table 4), 49.5\% mothers had low stress for inadequate explanation about the illness by the physician, $46.9 \%$ mothers had low stress for Inadequate explanation about the lab results \& diagnostic procedures by the physician, 78\% mothers had very high stress for giving the responsibility for monitoring IV fluids, $74.2 \%$ had very high stress for turning over responsibility for collecting samples to mothers by nursing staffs, $60.9 \%$ mothers had very high stress on lack of attention from nursing staffs about mother's problem and $68.5 \%$ had very high stress on lack of proper nutrition for hospitalized children.

Table 1: Stressors related to child factors according to likert scale

\begin{tabular}{|c|c|c|c|c|c|}
\hline Variables & $\begin{array}{l}\text { VH } \\
(\%)\end{array}$ & H (\%) & A (\%) & $L(\%)$ & $\begin{array}{l}\text { NS } \\
(\%)\end{array}$ \\
\hline $\begin{array}{l}\text { The child appears } \\
\text { lethargic,weak \& pale }\end{array}$ & $62.8 \%$ & $37.2 \%$ & - & - & - \\
\hline $\begin{array}{l}\text { Prolongation of } \\
\text { hospitalization }\end{array}$ & $58.1 \%$ & $23.8 \%$ & $16.2 \%$ & $1.9 \%$ & - \\
\hline The severity of disease & $56.1 \%$ & $27.6 \%$ & $5.8 \%$ & $10.5 \%$ & - \\
\hline Child's enabled to eat & $45.7 \%$ & $17.2 \%$ & $16.2 \%$ & $20.9 \%$ & - \\
\hline Fear of death & $38 \%$ & $36.1 \%$ & - & $25.9 \%$ & - \\
\hline $\begin{array}{l}\text { Uncertain try about } \\
\text { future of child's medical } \\
\text { condition }\end{array}$ & $63.8 \%$ & $20.9 \%$ & $15.3 \%$ & - & - \\
\hline Fear of relapse & $90.4 \%$ & $9.6 \%$ & - & - & - \\
\hline $\begin{array}{l}\text { Child irritability \& } \\
\text { crying }\end{array}$ & $88.6 \%$ & $3.8 \%$ & $5.7 \%$ & $1.9 \%$ & \\
\hline $\begin{array}{l}\text { Concern about IV fluids } \\
\text { \& tubes connected }\end{array}$ & $78 \%$ & $13.3 \%$ & $3.8 \%$ & $3.8 \%$ & $0.9 \%$ \\
\hline Child's pain & $83.8 \%$ & $4.8 \%$ & $3.8 \%$ & $7.6 \%$ & - \\
\hline $\begin{array}{l}\text { Concern about } \\
\text { laboratory \& imaging }\end{array}$ & $87.7 \%$ & $5.7 \%$ & $2.8 \%$ & $3.8 \%$ & - \\
\hline
\end{tabular}

(VH) Very High, (H) High, (A) Average, (L) Low, (NS) No Stress 
Table 2: Stressors related to social and economic aspects according to likert scale

\begin{tabular}{|l|r|r|r|r|r|}
\hline Variables & VH (\%) & H (\%) & A (\%) & L(\%) & $\begin{array}{r}\text { NS } \\
(\mathbf{\%})\end{array}$ \\
\hline $\begin{array}{l}\text { Failure to provide comfort to other children due } \\
\text { to child illness }\end{array}$ & $59 \%$ & $41 \%$ & - & - & - \\
\hline Problems related to drug unavailability & $16.2 \%$ & $11.4 \%$ & $38 \%$ & $34.4 \%$ & - \\
\hline Inability to pay the costs of treatment \& care & $44.7 \%$ & $16.2 \%$ & $20.9 \%$ & $18.2 \%$ & - \\
\hline Concern about academic \& school & $6.6 \%$ & $10.4 \%$ & $1.9 \%$ & $12.3 \%$ & $68.8 \%$ \\
\hline Fear of other children having the same disease & $55.2 \%$ & $0.1 \%$ & - & $2.8 \%$ & $41.9 \%$ \\
\hline Fear of job loss because of the child's disease & - & - & $5.8 \%$ & - & $94.2 \%$ \\
\hline Being away from work \& living place & $82.8 \%$ & $7.7 \%$ & - & $9.5 \%$ & - \\
\hline
\end{tabular}

(VH) Very High, (H) High, (A) Average, (L) Low, (NS) No Stress

Table 3: Stressors related to environmental factors according to likert scale

\begin{tabular}{|l|r|r|r|r|r|}
\hline Variables & VH (\%) & H (\%) & A (\%) & L(\%) & NS (\%) \\
\hline Noise pollution & $7.7 \%$ & $9.5 \%$ & $45.7 \%$ & $20 \%$ & $17.1 \%$ \\
\hline Crowded room \& the large number of children & - & - & - & $10.4 \%$ & $89.6 \%$ \\
\hline Uncomfortable beds & $25.7 \%$ & $17.1 \%$ & $29.5 \%$ & $17.1 \%$ & $10.6 \%$ \\
\hline Equipments & $31.4 \%$ & $54.2 \%$ & $6.6 \%$ & $5.7 \%$ & $2.1 \%$ \\
\hline Concern about unpleasant odors & $84.7 \%$ & - & $7.6 \%$ & $1.9 \%$ & $5.8 \%$ \\
\hline Unfamiliar environment & $59 \%$ & $29.5 \%$ & $11.5 \%$ & - & - \\
\hline Lack of adequate sanitation \& air pollution & $68.5 \%$ & $10.6 \%$ & $9.5 \%$ & $3.8 \%$ & $7.6 \%$ \\
\hline No game room for children to entertain & $46.6 \%$ & $16.1 \%$ & $10.4 \%$ & $3.1 \%$ & $23.8 \%$ \\
\hline No room to rest for visitor & $59 \%$ & $16.1 \%$ & - & $19 \%$ & $5.9 \%$ \\
\hline Shortage of blankets and linens & $49.5 \%$ & $18 \%$ & $20.9 \%$ & $7.6 \%$ & $4 \%$ \\
\hline
\end{tabular}

(VH) Very High, (H) High, (A) Average, (L) Low, (NS) No Stress

Table 4. Stressors related to hospital staffs according to likert scale

\begin{tabular}{|l|r|r|r|r|r|}
\hline Variables & VH (\%) & H (\%) & A (\%) & L(\%) & NS (\%) \\
\hline $\begin{array}{l}\text { Inadequate explanation about the illness by the } \\
\text { physician }\end{array}$ & $8.5 \%$ & $3.8 \%$ & $25.7 \%$ & $49.5 \%$ & $12.5 \%$ \\
\hline $\begin{array}{l}\text { Inadequate explanation about the lab results \& } \\
\text { diagnostic procedures by the physician }\end{array}$ & $8.5 \%$ & $4.7 \%$ & $27.6 \%$ & $46.9 \%$ & $12.3 \%$ \\
\hline $\begin{array}{l}\text { Giving the responsibility for monitoring IV } \\
\text { fluids }\end{array}$ & $78 \%$ & $10.4 \%$ & $9.5 \%$ & $2.1 \%$ & - \\
\hline $\begin{array}{l}\text { Turning over responsibility for collecting } \\
\text { samples to mothers by nursing staffs }\end{array}$ & $74.2 \%$ & $17.1 \%$ & $3.8 \%$ & $2.8 \%$ & $2.1 \%$ \\
\hline $\begin{array}{l}\text { Lack of attention from nursing staffs about } \\
\text { mother's problem }\end{array}$ & $60.9 \%$ & $18.1 \%$ & $15.2 \%$ & $0.9 \%$ & $4.9 \%$ \\
\hline $\begin{array}{l}\text { Lack of proper nutrition for hospitalized } \\
\text { children }\end{array}$ & $68.5 \%$ & $5.7 \%$ & $11.4 \%$ & $6.6 \%$ & $10.8 \%$ \\
\hline
\end{tabular}

(VH) Very High, (H) High, (A) Average, (L) Low, (NS) No Stress 


\section{DISCUSSION:}

The findings of the study showed that majority of mothers had very high stressors related to child factors $(62.8 \%$ child appears lethargic, $58.1 \%$ weak and pale, prolongation of hospitalization, $45.7 \%$ child's enabled to eat, $38 \%$ fear of death, $63.8 \%$ uncertain try about future of child's medical condition, and $90.4 \%$ fear of relapse). Around $88.6 \%$ mothers had very high stressors related to child irritability and crying, $78 \%$ mothers had very high stressors in concern about IV fluids and tubes connected, $83.8 \%$ had very for child's pain and $87.7 \%$ had very high concern about laboratory and imaging. In the study conducted by TEHRANI, Haghighi, Bazmamoun (2008) on pediatrics ward of Besat hospital in Hamedan, which showed that the stressors in mothers of hospitalized children the most influencing factor related to children's care was fear of death and the least one was about serum IV fluid and other connected tubes to the child. ${ }^{10}$

The findings of the study, stressors related to social and economic aspects, mothers had very high stressors for $59 \%$ for failure to provide comfort to other children due to child illness, $55.2 \%$ fear of other children having the same disease and $82.8 \%$ being away from work and living place. In the study conducted by Esmaeilzadeh (2001) in Qods hospital of Qazvin (Iran), the highest socio-economic stressor was the mother's worrying about other children left at home. ${ }^{11}$

The findings of the study stressors related to environmental factors, mothers having very high stress on $54.2 \%$ with equipments, $84.7 \%$ unfamiliar environment, $68.5 \%$ for lack of adequate sanitation and air pollution, $46.6 \%$ had very high stress related to no game room for children, 59\% had very high stress that no room to rest for visitor and $49.5 \%$ had very high stress regarding shortage of blankets and linens. In the study conducted done by Mwangi et al (2008) on 13 public hospitals in northern Tanzania, the most effective environmental stressors were crowded rooms, lack of food, poor sanitation and fear from transmission of infections from other children to their child. ${ }^{9}$ The study conducted by Soderback and Christensson, mothers' at the Central Hospital in Maputo,
Mozambique, Southeast Africa mothers complaint related to environmental factors were about lack of sanitation services. ${ }^{8}$

The findings of the study regarding stressors related to hospital staffs, $78 \%$ mothers had very high stress for giving the responsibility for monitoring IV fluids, $74.2 \%$ had very high stress for turning over responsibility for collecting samples to mothers by nursing staffs, $60.9 \%$ had very stress on lack of attention from nursing staffs about mother's problem and $68.5 \%$ had very high stress on lack of proper nutrition for hospitalized children. In the study conducted done by Mwangi et al (2008) on 13 public hospitals in northern Tanzania, most of the stressors related to the staff and employees were caused by an inadequate explanation and that mothers (in addition to their own basic needs such as nutrition and rest) expect, were involved in the decision-making process by the medical staffs and also take adequate explanation about healing process and invasive procedures. ${ }^{9}$

\section{CONCLUSION:}

Based on the study findings, it is concluded that mothers felt stress, psychological and emotional impact on their own behavior during their children hospitalization in this condition, mothers need understanding of their psychological and emotional problems wanted to obtain simplified explanation. So, special attention and professional training programs should be required for health care providers and nursing staffs regarding dealing with the stressors of mothers of hospitalized children.

\section{ACKNOWLEDGEMENT:}

Researchers deeply express their heartfelt thanks to all mothers who participated in the study for immense support and cooperation. Researchers express their deep and sincere gratitude to all those experts for their valuable judgment, constructive feedbacks and enlightening suggestions throughout the study.

\section{CONFLICT OF INTEREST: None}

\section{REFERENCES:}

1. Bonichini S, Axia G, Bornstein MH. Validation of the parent health locus of control scales in an Italian 
sample. Italian journal of pediatrics. 2009 Dec;35(1):13.

2. Commodari E. Children staying in hospital: a research on psychological stress of caregivers. Italian journal of pediatrics. 2010 Dec;36(1):40.

3. Keane TM, Taylor KL, Penk WE. Differentiating posttraumatic stress disorder (PTSD) from major depression $(M D D)$ and generalized anxiety disorder (GAD). Journal of Anxiety Disorders. 1997 May 1;11(3):317-28.

4. Kanner AD, Coyne JC, Schaefer C, Lazarus RS. Comparison of two modes of stress measurement: Daily hassles and uplifts versus major life events. Journal of behavioral medicine. 1981 Mar 1;4(1):1-39.

5. Shields L, Hallström IK. We have needs, too: parental needs during a child's hospitalisation. Online Brazilian Journal of Nursing. 2004 Nov 27;3(3):3-16.

6. Hallström I, Runesson I, Elander G. Observed parental needs during their child's hospitalization. Journal of pediatric nursing. 2002 Apr 1;17(2):140-8.

7. Little L. Differences in stress and coping for mothers and fathers of children with Asperger's syndrome and nonverbal learning disorders. Pediatric nursing. 2002 Nov 1;28(6):565.

8. Söderbäck M, Christensson K. Family involvement in the care of a hospitalised child: A questionnaire survey of Mozambican family caregivers. International Journal of Nursing Studies. 2008 Dec 1;45(12):1778-88.

9. Mwangi R, Chandler C, Nasuwa F, Mbakilwa H, Poulsen A, Bygbjerg IC, Reyburn H. Perceptions of mothers and hospital staff of paediatric care in 13 public hospitals in northern Tanzania. Transactions of the Royal Society of Tropical Medicine and Hygiene. 2008 Aug 1;102(8):805-10.

10. TEHRANI TH, Haghighi M, Bazmamoun H. Effects of stress on mothers of hospitalized children in a hospital in Iran. Iranian journal of child neurology. 2012;6(4):39.

11. Esmaeilzadeh H. Stressors of mothers of hospitalized neonates in Qods hospital.

12. Lazarus RS, Folkman S. Psychological stress and the coping process McGraw Hill New York Google Scholar.

13. Greer AJ, Gulotta CS, Masler EA, Laud RB. Caregiver stress and outcomes of children with pediatric feeding disorders treated in an intensive interdisciplinary program. Journal of Pediatric Psychology. 2007 Dec 3;33(6):612-20.

14. Schalkers I, Enthoven C, Bunders J, Dedding C. When to invest in clinical guidelines for children? A practice oriented tool to facilitate decision-making. Journal of evaluation in clinical practice. 2017 Feb;23(1):79-88.

15. Garro A, Thurman SK, Kerwin ME, Ducette JP. Parent/caregiver stress during pediatric hospitalization for chronic feeding problems. Journal of Pediatric Nursing. 2005 Jul 1;20(4):268-75.

16. Burke SO, Harrison MB, Kauffmann E, Wong C. Effects of stress-point intervention with families of repeatedly hospitalized children. Journal of family nursing. 2001 May;7(2):128-58.

17. Knafl KA, Havill NL, Leeman J, Fleming L, Crandell $J L$, Sandelowski M. The nature of family engagement in interventions for children with chronic conditions. Western journal of nursing research. 2017 May;39(5):690-723.

18. Ogden Burke S, Handley-Derry MH, Costello EA, Kauffmann E, Dillon MC. Stress-point intervention for parents of repeatedly hospitalized children with chronic conditions. Research in nursing \& health. 1997 Dec;20(6):475-85. 